\author{
ISSN: 2757-6485
}

$2021 \& 2$ (2)

\title{
Öğretmenlerin Pandemi (Covid19) Süreci Öncesi ve Pandemi Döneminde Sağlıklı Beslenmeye Karşı Tutum Düzeylerinin İncelenmesi
}

\author{
"Examination of Teachers' Attitudes towards Healthy Nutrition Before and During \\ the Pandemic (Covid19) Process"'
}

\author{
Ayhan KAYABAŞI ${ }^{1}$ \& Hüseyin EROĞLU² \& Taha Berk OKYAZ ${ }^{3}$ \& Mehmet Furkan ŞAHIN ${ }^{4}$
}

\author{
ARASTIRMA MAKALESI \\ Tarihçe \\ Yayın Geliş Tarihi: 17 Aralık 2020 \\ Kabul Tarihi: 24 Ağustos 2021 \\ Online Yayın Tarihi: 31 Ağustos 2021 \\ Doi: http://dx.doi.org/10.29228/anatoliasr.15 \\ Yazarlarla İletişim \\ 1- (Cotrresponded Author) KSÜ, Spor Bilimleri \\ Fakültesi, Beden Eğitimi ve Spor Anabilim Dalı, \\ Doktora Programı Öğrencisi, Kahramanmaraş, \\ TÜRKIYE \\ kayabasiayhan@gmail.com \\ https://orcid.org/ 0000-0001-7570-4748 \\ 2- Kahramanmaraş Sütçü İmam Üniversitesi, Spor \\ Bilimleri Fakültesi, Beden Eğitimi ve Spor Anabilim \\ Dalı, Kahramanmaraș, TÜRKIYE \\ eroglu1@gmail.com \\ https://orcid.org/ 0000-0002-6124-8187 \\ 3- Kahramanmaraş Sütçü İmam Üniversitesi, Spor \\ Bilimleri Fakültesi, Beden Eğitimi ve Spor Anabilim \\ Dalı, Yüksek Lisans Programı Öğrencisi \\ Kahramanmaraș, TÜRKIYE \\ tahaberk.okyaz@hotmail.com \\ https://orcid.org/ 0000-0001-8855-6043 \\ 4- Muș Alparslan Üniversitesi, Spor Bilimleri \\ Fakültesi, Antrenörlük Eğitimi, Mus TÜRKIYE \\ f.sahin@alparslan.edu.tr \\ https://orcid.org/ 0000-0003-4614-4002
}

\section{Yazar Katkıları}

Tüm yazarlar çalışmanın konseptine ve tasarımına katkıda bulundu.

\section{Finansman}

$\mathrm{Bu}$ çalşsma herhangi bir kurum/kuruluştan maddi destek almadi.

\section{Çıkar Çatışması}

Yazarlar çıkar çatışması olmadığını beyan ediyorlar.

Şeffaflık

Yazarlar, çalışmada hiçbir hayati özelliğin ihmal edilmediğini, dürüst, doğru ve şeffaf bir anlatım ile raporlaştırıldığını ve herhangi bir tutarsızlık olmadığını beyan etmişlerdir.

Etik

$\mathrm{Bu}$ çalışmada bilimsel etik kriterlerine uyulmuştur.

Citation

Kayabasi, A., Eroğlu H., Okyaz T. B., Sahin M. F. (2021). Öğretmenlerin Pandemi (Covid 19) Süreci Öncesi ve Pandemi Döneminde Sağlıklı Beslenmeye Karş1 Tutum Düzeylerinin İncelenmesi, Anatolia Sport Research, 2(2): 46-52.

Copyright $(C) 2021$ by Anatolia Sport Research

\section{ÖZET}

Amaç: Öğretmenlerin pandemi(Covid19) süreci öncesi ve pandemi sürecinde sağlıklı beslenmeye yönelik tutum ve davranışlarının farklı değişkenler açısından araştııılması amaçlanmıştır

Materyal ve Metod: Araştırmaya Kahramanmaraş ilinde kamu ve özel okullarda görev yapan öğretmenlerden 98 kadın ve 144 erkek katılmıştır. Araştırmanın verilerini toplamak için, Demir ve Cicioğlu (2019) nun yaptığı Sağlıklı Beslenmeye İlişkin Tutum Ölçeği (SBİTÖ) ile Kişisel veri formu kullanılmıştır. Araştırmanın verileri parametrik test uygulayacak kadar normal dağılım göstermediğinden Kruskal-Wallis $H$, Mann-Whitney $U$ testlerinden ve Descriptives test sonuçlarından yararlanılmıştır. İstatistikî analizlerde anlamlılık düzeyi $\mathrm{p}<0.05$ olarak seçilmiştir. Bulgular:Araştırmada, öğretmenlerin pandemi öncesi ve pandemi sürecinde sağlıklı beslenmeye karşı tutum düzeylerini değerlendirmek için alınan verilerin ortalamalarına bakıldığında olumlu yönde bir farkındalık kazandırdığı belirlenmiş̧tir. Araştırma bulgularına göre; cinsiyet, medeni hali ve branş değişkenine göre istatistiksel olarak anlamlı farklılık görülmüştür.

Sonuç:Kadın ve bekar öğretmenlerin sağlıklı beslenmeye karşı tutum düzeylerinin yüksek olduğu, pandemi sürecinde sınıf öğretmenlerinin sağlıklı beslenme tutum düzeylerinin daha yüksek seviyeye ulaştıkları yordanmıştır.

Anahtar Kelimeler: Covid 19, Pandemi, Sağlıklı Beslenme,

\section{ABSTRACT}

Aim: It is the study of teachers' attitudes and behaviors towards healthy diet before the pandemic (Covid19) process and during the pandemic process in terms of different variables.

Material and Method: This study, 98 female and 144 male teachers working in public and private schools in Kahramanmaraş voluntarily participated. In order to collect the data of the study, the Attitudes towards Healthy Nutrition Scale (HSTO) by Demir and Cicioğlu (2019) and a personal data form were used. Since the data of the study did not show a normal distribution enough to apply parametric tests, Kruskal-Wallis H, Mann-Whitney U tests and Descriptives test results were used. In statistical analysis, the level of significance was chosen as $\mathrm{p}<0.05$.

Results: In the study, it was determined that the average of the data obtained to evaluate the attitudes of teachers towards healthy diet before and during the pandemic period gave a positive awareness. According to the research findings; there was a statistically significant difference related to the gender, marital status and branch variables.

Conclusions: It has been predicted that female and single teachers have positive attitudes towards healthy diet, and that elementary school teachers' attitudes towards healthy diet have reached a higher level during the pandemic process.

Keywords: Covid 19, Pandemic, Healthy Eating 


\section{GíRiş}

Günümüz dünyasını her yönüyle etkileyen salgın bir hastalık olan SARS-CoV-2 (ciddi akut solunum sendromu koronavirüs-2) ilk olarak Çin'in Hubai bölgesindeki Wuhan kentinde nedeni bilinmeden ortaya çıkan kısaltılmış adı covid19 olarak bilinen bir solunum yolu hastalığıdır (Muscogiuri,G. vd., 2020). Dünya sağlık örgütü 11 Mart 2020 de uluslar arası bir çağrıda bulunarak pandemi ilan etmiş̦tir (Cintoni, M. vd. , 2020). Pandemi bir terim olarak, bütün kıtaları etkileyecek bulaşıcı riski yüksek hastalık olarak tanımlanmıştır ( Til, A., 2020). Dünya genelinde hızlı bir şekilde yayılan Covid 19 hastalığının ülkemizde 11 Mart 2020 tarihinde Sağlık Bakanlığı tarafından hastalık belirtilerini taşıyan kişilerin olduğunu açıklamıştır (Arı,A.G., \& Kanat,M.H. 2020).

Canlıların en temel ihtiyaçlarından biri olan beslenme, vücudun gelişmesi, yaşamın devam ettirilmesi ve hastalıklardan korunmak için besinlerin yeterli miktarda tüketilmesidir (Vançelik, S. Vd.,2007). Günümüze kadar yapılmış çalışmalar göstermiştir ki, yetersiz ve gelişi güzel beslenen bireylerde vücut gelişiminin yanında zihinsel gelişme üzerinde de olumsuz etkileri olmuştur (Tokgöz, P. Vd.,1995). Pandemi döneminde daha önceki deneyimlere ek olarak bireylerin beslenmeye karş1 tutumları; COVID-19'unkine benzer büyüklükteki bir pandemi karşısında halk sağlığı yaklaşımlarının etkinliğini artırmak için hayati belirleyicilerdir (Hislop, T. G. vd.,2006). Aslında, zayıf beslenme kalitesi vücudun tüm formuyla ilişkilendirilmiştir (Reissman, D.vd.2006).

Öğretmenler, gelecek nesillere belirlenmiş planlar dâhilinde yön veren ve davranışlarıyla göz önünde olan profesyonel bireylerdir. Öğretmenlerin, toplumun maruz kaldığ 1 bu kritik dönemde mesleğinin gerekleri nispetinde, çoğu aile ile iletişim gayreti içerisinde bulunmaktadır ( Çakın, M., \& Akyavuz, E. K. 2020). Bu iletişim içerisinde bulunduğu kritik durumun farkındalığının oluşmasında etkili olduğu düşünülmektedir. Toplumun bu kritik süreçte dikkat etmesi gereken koruyucu tedbirler arasında maske, mesafe, temizlik ve vücudu zayıf hale düşürmeyecek şekilde dengeli beslenme bulunmaktadır. Pandemi döneminde, virüsün yayılmasını önlemek amacıyla, insanların birbiriyle temasını kesmelerini ve imkânları ölçüsünde karantinaya almaları gerektiği vurgulanmaktadır. $\mathrm{Bu}$ karantinaya almak, şehir yaşamında bireyi haraketsiz bir yaşama sürüklemektedir. Hareketsiz yaşamın en büyük tehlikesi kilo alma ve obezitedir (Dilber, A., \& Dilber, F. 2020).Araştırmada önemli bir grupla etkiletişim içerisinde olan öğretmenlerin pandemi öncesi ve pandemi sürecindeki beslenme tutum ve davranışlarının değişimini incelemek ve beslenme bilgisi hakkında eğitim alan öğretmenlerin farklı belirleyici etkilerinin olup olmadığını belirlemek amacıyla yapılmıştır.

\section{MATERYAL VE METOD}

\section{Araştırma Modeli}

Araştırma betimsel nitelikte tarama yöntemi uygulanan bu çalışma, Kahramanmarş Sütçü İmam Üniversitesi etik kurulu tarafından alınan karar ( karar no: 04/2021.07) doğrultusunda çalışmaya devam edilmiştir.

\section{Araştırma Grubu}

Bu çalışmanın araştırma grubu, 2020-2021 eğitim öğretim y1lında Kahramanmaraş bölgesinde kamu ve özel okullarda aktif olarak görev yapan öğretmenlerden gönüllü olarak katılım sağlayan 98 kadın ve 144 erkek olmak üzere toplam 242 kişi oluşturmaktadır. 


\section{Veri Toplama Araçları}

Bu çalışmada, öğretmenlerin pandemi süreci öncesi ve pandemi sürecinde sağlıklı beslenmeye ilişkin tutumları hakkında bilgileri toplamak için araştırmacı tarafından hazırlanan kişisel bilgi formu ile geçerlilik ve güvenirlilik çalışmasını Demir ve Cicioğlu (2019) nun yaptığı Sağlıklı Beslenmeye İlişkin Tutum Ölçeği (SBİTÖ) kullanılmıştır. İki ayrı süreç için aynı sorular sorulmuş olup, özellikle öğretmenlerin pandemi öncesi süreci belirlemek için bireylerin bulunduğu süreçten bağımsız, daha önceki tutumlarını gözden geçirip o şekilde cevaplamaları istenmiştir. Bu ölçek; 21 madde olup dört faktör ( Beslenme hakkında bilgi, Beslenmeye yönelik tutum, Olumlu beslenme alışkanlığı ve Kötü beslenme alışkanlığı) olarak değerlendirmeye alınmıştır. Envanterde 5 li likert tipi cevaplama anahtarı kullanılmıştır. Çalışma grubundan elde edilen verilen Cronbach alfa kat sayısı 0,74 olarak bulunmuştur. Veriler SPSS 24 programına yüklenerek değerlendirilmiştir. Örneklem gruplarından alınan verilere Kolmogorow-Smirnov testi uygulanarak normal dağılıp dağılmadığı belirlenmiştir. Araştırmanın verileri parametrik test uygulayacak kadar normal dağılım göstermediğinden, ikili karşılaştırmalı değişkenlerin değerlendirilmesinde Mann-Whitney U testi, ikiden fazla grup değişkenin analizinde Kruskal Wallis H testi ve Descriptives test sonuçlarından yararlanılmıştır. Yapılan çalışmada, anlamlılık düzeyi $\mathrm{p}<0,05$ olarak alınmıştır.

\section{BULGULAR}

Tablo 1. Katılımclların Demografik Özellikleri ve Betimsel İstatistikleri

\begin{tabular}{llcc}
\hline \multirow{2}{*}{ Değişkenler } & & $\mathbf{N}$ & $\mathbf{\%}$ \\
\multirow{2}{*}{ CINSIYYET } & Kadın & 98 & 40,5 \\
\cline { 2 - 4 } & Erkek & 144 & 59,5 \\
\hline \multirow{2}{*}{ BRANŞ̦ } & Evli & 230 & 95 \\
\cline { 2 - 4 } & Bekar & 12 & 5 \\
& Bed. Eğit. Öğrt. & 76 & 31,4 \\
\cline { 2 - 4 } & Branş Öğrt. & 108 & 44,6 \\
\cline { 2 - 4 } & Ana sınıfı Öğrt. & 12 & 5 \\
\cline { 2 - 4 } & Sinıf Öğrt. & 46 & 19 \\
\hline
\end{tabular}

Araştırmaya 242 öğretmen değerlendirmeye alınmıştır. öğretmenlerin cinsiyet, medeni hali ve branş değiş̧kenlerine göre dağılımı tablo 1 de belirtilmiştir. Bu verilere göre, araştırmaya katılan öğretmenlerin \% 40,5 i (n: 98) kadın öğretmen, \% 59,5 i (n:144) erkek öğretmen, \% 95'i(n: 230) evli öğretmen, \% 5'i (n:12) bekar öğretmen, \%31,4'ü (n:76) beden eğitimi ve spor öğretmeni, \%44,6' s1 (n:108) çeşitli branşlarda öğretmen,\% 5' i (n:46) anasınıfı öğretmeni ve \%19'u sınıf öğretmeni olarak görev yapan bireylerden oluşmaktadır.

Tablo 2. Araştırma grubunun Cinsiyet değişkenine göre analiz sonuçları

\begin{tabular}{|c|c|c|c|c|c|c|c|}
\hline & Cinsiyet & & $\mathbf{N}$ & $\begin{array}{l}\text { Sira } \\
\text { ort. }\end{array}$ & $\begin{array}{c}\text { Sira } \\
\text { Toplamı }\end{array}$ & $\mathbf{U}$ & $\mathbf{p}$ \\
\hline \multirow{6}{*}{ 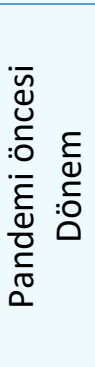 } & \multirow{2}{*}{$\begin{array}{l}\text { Beslenme } \\
\text { Hakkında } \\
\text { Bilgi }\end{array}$} & Kadın & 98 & 122,74 & 12029,00 & \multirow[t]{2}{*}{6934,00} & \multirow[t]{2}{*}{0,81} \\
\hline & & Erkek & 144 & 120,65 & 17374,00 & & \\
\hline & \multirow{2}{*}{$\begin{array}{l}\text { Beslenmeye } \\
\text { Yönelik } \\
\text { Tutum }\end{array}$} & Kadın & 98 & 138,19 & 13543,00 & \multirow[t]{2}{*}{5420,00} & \multirow[t]{2}{*}{$0,00 *$} \\
\hline & & Erkek & 144 & 110,14 & 15860,00 & & \\
\hline & \multirow{2}{*}{$\begin{array}{l}\text { Olumlu } \\
\text { Beslenme } \\
\text { Alışkanlığı }\end{array}$} & Kadın & 98 & 124,54 & 12205,00 & \multirow[t]{2}{*}{6758,00} & \multirow[t]{2}{*}{0,57} \\
\hline & & Erkek & 144 & 119,43 & 17198,00 & & \\
\hline
\end{tabular}




\begin{tabular}{|c|c|c|c|c|c|c|c|}
\hline & \multirow{2}{*}{$\begin{array}{l}\text { Kötü } \\
\text { Beslenme } \\
\text { Alışkanlığı }\end{array}$} & Kadın & 98 & 117,09 & 11475,00 & \multirow[t]{2}{*}{6624,00} & \multirow[t]{2}{*}{0,41} \\
\hline & & Erkek & 144 & 124,50 & 17928,00 & & \\
\hline \multirow{8}{*}{ 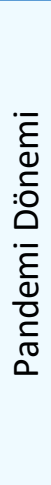 } & \multirow{2}{*}{$\begin{array}{l}\text { Beslenme } \\
\text { Hakkında } \\
\text { Bilgi }\end{array}$} & Kadın & 98 & 131,64 & 12901,00 & \multirow[t]{2}{*}{6062,00} & \multirow[t]{2}{*}{$0,017 *$} \\
\hline & & Erkek & 144 & 114,60 & 16502,00 & & \\
\hline & \multirow{2}{*}{$\begin{array}{l}\text { Beslenmeye } \\
\text { Yönelik } \\
\text { Tutum }\end{array}$} & Kadın & 98 & 127,85 & 12529,00 & \multirow[t]{2}{*}{6434,00} & \multirow[t]{2}{*}{0,24} \\
\hline & & Erkek & 144 & 117,18 & 16502,00 & & \\
\hline & \multirow{2}{*}{$\begin{array}{l}\text { Olumlu } \\
\text { Beslenme } \\
\text { Alışkanlığı }\end{array}$} & Kadın & 98 & 129,79 & 12719,00 & \multirow[t]{2}{*}{6244,00} & \multirow[t]{2}{*}{0,12} \\
\hline & & Erkek & 144 & 115,86 & 16684,00 & & \\
\hline & \multirow{2}{*}{$\begin{array}{l}\text { Kötü } \\
\text { Beslenme } \\
\text { Alışkanlığı }\end{array}$} & Kadın & 98 & 124,52 & 12203,00 & \multirow[t]{2}{*}{6760,00} & \multirow[t]{2}{*}{0,57} \\
\hline & & Erkek & 144 & 119,44 & 17200,00 & & \\
\hline
\end{tabular}

$\left({ }^{*} \mathrm{p}<0.05\right)(\mathrm{KÖ})$ :

Tablo 2'e göre, araştırma grubunun pandemi dönemi öncesi ve pandemi dönemi içerisinde sağllklı beslenmeye karşı tutum düzeyleri alt faktörleri cinsiyet değişkenine göre incelendiğinde pandemi öncesi beslenmeye yönelik tutum ( $Z:-3,067, p<0,05)$ ve pandemi sürecinde beslenme hakkında bilgi ( $Z:-1,941$, $\mathrm{p}<0,05)$ alt faktörlerinde istatistiksel olarak anlamlı farklılık görülmüsstür $(\mathrm{p}<0,05)$.

Tablo 3. Araştırma grubunun Medeni durum değişkenine göre analiz sonuçları

\begin{tabular}{|c|c|c|c|c|c|c|c|}
\hline \multicolumn{3}{|c|}{ Medeni Durum } & $\mathbf{N}$ & Sira & Sira & $\mathbf{U}$ & p \\
\hline \multirow{8}{*}{ 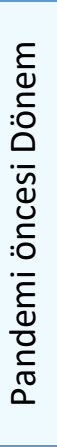 } & \multirow{2}{*}{$\begin{array}{l}\text { Beslenme } \\
\text { Hakkında Bilgi }\end{array}$} & Evli & 230 & 121,49 & 27943,00 & \multirow[t]{2}{*}{1378,00} & \multirow[t]{2}{*}{0,99} \\
\hline & & Bekâr & 12 & 121,67 & 1460,00 & & \\
\hline & \multirow{2}{*}{$\begin{array}{l}\text { Beslenmeye } \\
\text { Yönelik Tutum }\end{array}$} & Evli & 230 & 117,93 & 27123,00 & \multirow[t]{2}{*}{558,00} & \multirow[t]{2}{*}{$0,00 *$} \\
\hline & & Bekâr & 12 & 190,00 & 2280,00 & & \\
\hline & \multirow{2}{*}{$\begin{array}{l}\text { Olumlu } \\
\text { Beslenme } \\
\text { Alışkanlığ } 1\end{array}$} & Evli & 230 & 121,18 & 27871,00 & \multirow[t]{2}{*}{1306,00} & \multirow[t]{2}{*}{0,75} \\
\hline & & Bekâr & 12 & 127,67 & 1532,00 & & \\
\hline & \multirow{2}{*}{$\begin{array}{l}\text { Kötü Beslenme } \\
\text { Alışkanlığı }\end{array}$} & Evli & 230 & 119,05 & 27381,00 & \multirow[t]{2}{*}{816,00} & \multirow[t]{2}{*}{0,016} \\
\hline & & Bekâr & 12 & 168,50 & 2022,00 & & \\
\hline \multirow{8}{*}{ 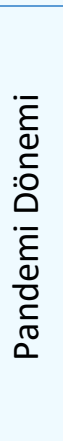 } & \multirow{2}{*}{$\begin{array}{l}\text { Beslenme } \\
\text { Hakkında Bilgi }\end{array}$} & Evli & 230 & 121,33 & 27907,00 & \multirow[t]{2}{*}{1342,00} & \multirow[t]{2}{*}{0,86} \\
\hline & & Bekâr & 12 & 124,67 & 1496,00 & & \\
\hline & \multirow{2}{*}{$\begin{array}{l}\text { Beslenmeye } \\
\text { Yönelik Tutum }\end{array}$} & Evli & 230 & 118,67 & 27293,00 & \multirow[t]{2}{*}{728,00} & \multirow[t]{2}{*}{$0,00 *$} \\
\hline & & Bekâr & 12 & 175,83 & 2110,00 & & \\
\hline & \multirow{2}{*}{$\begin{array}{l}\text { Olumlu } \\
\text { Beslenme } \\
\text { Alışkanlığı }\end{array}$} & Evli & 230 & 121,23 & 27883,00 & \multirow[t]{2}{*}{1318,00} & \multirow[t]{2}{*}{0,79} \\
\hline & & Bekâr & 12 & 126,67 & 1520,00 & & \\
\hline & \multirow{2}{*}{$\begin{array}{l}\text { Kötü Beslenme } \\
\text { Alışkanlığ } 1\end{array}$} & Evli & 230 & 121,12 & 27857,00 & \multirow[t]{2}{*}{1292,00} & \multirow[t]{2}{*}{0,70} \\
\hline & & Bekâr & 12 & 128,83 & 1546,00 & & \\
\hline
\end{tabular}

$(* \mathrm{p}<0.05)$

Tablo 3'e göre araştırma grubunun pandemi dönemi öncesi ve pandemi dönemi içerisinde sağlıklı beslenmeye karşı tutum düzeyleri alt faktörleri incelendiğinde öğretmenlerin pandemi dönemi öncesi beslenmeye yönelik tutum( $\mathrm{Z}:-3,485, \mathrm{p}<0,05)$, pandemi dönemi öncesi kötü beslenme alışkanlığı ( $\mathrm{Z}$ :$2,406, p<0,05)$ ve pandemi dönemi içerisinde beslenmeye yönelik tutumları $(Z:-2,764, p<0,05)$ Medeni durum değişkenine göre istatistiksel olarak anlamlı bir farklılık olduğu tespit edilmiştir $(p<0,05)$. 
Tablo 4. Araştırma grubunun Branş değişkenine göre analiz sonuçları

\begin{tabular}{|c|c|c|c|c|c|c|c|c|}
\hline & Branşlar & & $\mathbf{N}$ & $\begin{array}{l}\text { Sira } \\
\text { ort. }\end{array}$ & Ss. & $\mathrm{X} 2$ & $\mathbf{p}$ & $\begin{array}{c}\text { Fark U } \\
\text { Testi }\end{array}$ \\
\hline \multirow{16}{*}{ 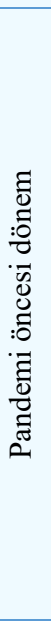 } & \multirow{4}{*}{$\begin{array}{l}\text { Beslenme } \\
\text { Hakkında } \\
\text { Bilgi }\end{array}$} & 1) Bed. Eğit. Öğrt. & 76 & 153,79 & 0,75 & \multirow[t]{4}{*}{31,411} & \multirow[t]{4}{*}{$0,000^{*}$} & \multirow[t]{4}{*}{$1>2$} \\
\hline & & 2)Branş Öğrt. & 108 & 97,20 & 0,80 & & & \\
\hline & & 3)Ana sınıfi Öğrt. & 12 & 134,83 & 0,50 & & & \\
\hline & & 4)Sınıf Öğrt. & 46 & 121,72 & 1,05 & & & \\
\hline & \multirow{4}{*}{$\begin{array}{l}\text { Beslenmey } \\
\text { e Yönelik } \\
\text { Tutum }\end{array}$} & 1)Bed. Eğit. Öğrt. & 76 & 109,50 & 0,72 & \multirow[t]{4}{*}{23,167} & \multirow[t]{4}{*}{$0,000^{*}$} & $2>1$ \\
\hline & & 2)Branş Öğrt. & 108 & 144,02 & 0,80 & & & $2>4$ \\
\hline & & 3)Ana sınıfi Öğrt. & 12 & 117,50 & 0,57 & & & \\
\hline & & 4)Sınıf Öğrt. & 46 & 89,50 & 0,77 & & & \\
\hline & \multirow{4}{*}{$\begin{array}{l}\text { Olumlu } \\
\text { Beslenme } \\
\text { Alışkanlığ } 1\end{array}$} & 1)Bed. Eğit. Öğrt. & 76 & 138,13 & 0,64 & \multirow[t]{4}{*}{16,729} & \multirow[t]{4}{*}{$0,001 *$} & $1>2$ \\
\hline & & 2)Branş Öğrt. & 108 & 101,19 & 0,69 & & & $4>2$ \\
\hline & & 3)Ana sınıfi Öğrt. & 12 & 130,17 & 0,44 & & & \\
\hline & & 4)Sınıf Öğrt. & 46 & 139,46 & 0,68 & & & \\
\hline & \multirow{4}{*}{$\begin{array}{l}\text { Kötü } \\
\text { Beslenme } \\
\text { Alışkanlığı }\end{array}$} & 1)Bed. Eğit. Öğrt. & 76 & 124,34 & 0,92 & \multirow[t]{4}{*}{21,138} & \multirow[t]{4}{*}{$0,000^{*}$} & $1>4$ \\
\hline & & 2)Branș Öğrt. & 108 & 136,06 & 0,66 & & & $2>4$ \\
\hline & & 3)Ana sınıfı Öğrt. & 12 & 129,83 & 0,71 & & & $3>4$ \\
\hline & & 4)Sınıf Öğrt. & 46 & 80,46 & 0,44 & & & \\
\hline \multirow{16}{*}{ 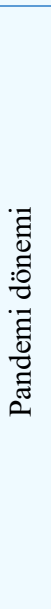 } & \multirow{4}{*}{$\begin{array}{l}\text { Beslenme } \\
\text { Hakkında } \\
\text { Bilgi }\end{array}$} & 1)Bed. Eğit. Öğrt. & 76 & 138,97 & 0,52 & \multirow[t]{4}{*}{24,736} & \multirow[t]{4}{*}{$0,000 *$} & $1>2$ \\
\hline & & 2)Branş Öğrt. & 108 & 97,72 & 0,61 & & & $3>2$ \\
\hline & & 3)Ana sinıfı Öğrt. & 12 & 137,50 & 0,46 & & & $4>2$ \\
\hline & & 4)Sınıf Öğrt. & 46 & 144,28 & 0,61 & & & \\
\hline & \multirow{4}{*}{$\begin{array}{l}\text { Beslenmey } \\
\text { e Yönelik } \\
\text { Tutum }\end{array}$} & 1)Bed. Eğit. Öğrt. & 76 & 112,74 & 0,80 & \multirow[t]{4}{*}{14,010} & \multirow[t]{4}{*}{$0,003^{*}$} & $2>1$ \\
\hline & & 2)Branş Öğrt. & 108 & 139,00 & 0,84 & & & $2>4$ \\
\hline & & 3)Ana sınıfi Öğrt. & 12 & 115,83 & 0,25 & & & \\
\hline & & 4)Sınıf Öğrt. & 46 & 96,37 & 1,08 & & & \\
\hline & \multirow{4}{*}{$\begin{array}{l}\text { Olumlu } \\
\text { Beslenme } \\
\text { Alışkanlığı } 1\end{array}$} & 1)Bed. Eğit. Öğrt. & 76 & 131,97 & 0,52 & \multirow[t]{4}{*}{17,062} & \multirow[t]{4}{*}{$0,001 *$} & $1>2$ \\
\hline & & 2)Branş Öğrt. & 108 & 101,78 & 0,60 & & & $3>2$ \\
\hline & & 3)Ana sınıfı Öğrt. & 12 & 133,67 & 0,30 & & & $4>2$ \\
\hline & & 4)Sınıf Öğrt. & 46 & 147,33 & 0,68 & & & \\
\hline & \multirow{4}{*}{$\begin{array}{l}\text { Kötü } \\
\text { Beslenme } \\
\text { Alışkanlığ1 }\end{array}$} & 1)Bed. Eğit. Öğrt. & 76 & 103,08 & 0,67 & \multirow[t]{4}{*}{17,200} & \multirow[t]{4}{*}{$0,001^{*}$} & $2>1$ \\
\hline & & 2)Branş Öğrt. & 108 & 141,26 & 0,70 & & & $2>4$ \\
\hline & & 3)Ana sınıfi Öğrt. & 12 & 126,67 & 0,62 & & & \\
\hline & & 4)Sınıf Öğrt. & 46 & 104,20 & 0,92 & & & \\
\hline
\end{tabular}

$\left({ }^{*} \mathrm{p}<0.05\right)$

Tablo 4'e göre araştırma grubunun pandemi dönemi öncesi ve pandemi dönemi içerisinde sağlıklı beslenmeye karşı tutum düzeyleri incelendiğinde öğretmenlerin branş özellikleri değişkenine göre; pandemi dönemi öncesi beslenme hakkında bilgi $\left(\mathrm{X}^{2}: 31,411, \mathrm{p}<0,05\right)$, pandemi dönemi öncesi beslenmeye yönelik tutum $\left(X^{2}: 23,167, p<0,05\right)$, pandemi dönemi öncesi olumlu beslenme alışkanlığ (X2 : 16,729, p<0,05), pandemi dönemi öncesi Kötü Beslenme Alışkanlığı $\left(X^{2}: 21,138, p<0,05\right)$, pandemi dönemi Beslenme Hakkında Bilgi $\left(\mathrm{X}^{2}: 24,736, \mathrm{p}<0,05\right)$, pandemi dönemi içerisinde beslenmeye yönelik tutum $\left(X^{2}: 14,010, p<0,05\right)$, pandemi döneminde Olumlu Beslenme Alışkanlığı $\left(X^{2}\right.$ $: 17,062, \mathrm{p}<0,05)$ ve pandemi döneminde Kötü Beslenme Alışkanlığı $\left(X^{2}: 17,200, p<0,05\right)$ alt faktörlerinde istatistiksel olarak anlamlı bir farklılık görülmüştür( $\mathrm{p}<0,05)$.

\section{TARTISSMA VE SONUÇ}

Araştırmanın genel yapısı içerisinde öğretmenlerin, cinsiyet, medeni hali ve kurum içerisindeki branşına yönelik pandemi süreci öncesi ve pandemi süreci içerisinde sağlıklı beslenmeye yönelik tutumlarının ne derece değişiklik gösterdiğine cevap aranmıştır.

Araştırma grubunun, pandemi öncesi ve pandemi süreci için vermiş olduğu verilerin ortalamalarına bakıldığında sağlıklı beslenme alışkanlığı tutum düzeyinin kısmen olumlu yönde değişiklik gösterdiği belirlenmiştir. 
Araştırmaya verilen cevaplar neticesinde öğretmenlerin cinsiyet değişkenine göre incelendiğinde, pandemi öncesi süreçteki sağlıklı beslenmeye karşı tutum ölçeği alt boyutlarından beslenmeye karş1 tutum ve pandemi sürecinde öğretmenlerin sağlıklı beslenmeye karşı tutum ölçeği alt boyutlarından beslenme hakkında bilgi düzeyinde istatistiksel olarak anlamlı farklılık görülmüştür. Bu farklılık puan ortalamalarına bakıldığında kadın öğretmenlerin lehine olduğu belirlenmiştir. Bu araştırmayı pandemi öncesi süreçte yapılan Özenoğlu ve arkadaşları (2020)' nın yetişkinler üzerine yapmış olduğu çalışmada cinsiyet değişkenine göre kadınların lehine anlamlı farklılık görülmüşken Gökay (2020)'ın spor salonlarına giden bireyler üzerine yapmış olduğu çalışma ile Dinç (2021)'in spor bilimleri öğrencileri üzerine yapmış olduğu çalışmada cinsiyet değişkenine göre istatistiksel olarak anlamlı farklılık görülmemiştir. Araştırma verilerinin kadın öğretmenlerin lehine sonuç vermesi, kadınların ailesinin beslenme tutumlarına yön veren ana etken olmasından kaynaklandığı düşünülünebilir.

Araştırmada öğretmenlerin medeni durum değişkenine göre sağlıklı beslenme tutum düzeylerine bakıldığında alt boyutlardan pandemi öncesi beslenmeye yönelik tutum ve kötü beslenme alışkanlığı, pandemi sürecinde beslenmeye yönelik tutum düzeylerinin ortalamalarına göre istatistiksel olarak anlamlı farklılık görülmüştür. Bu farklılık evlilerin aksine bekâr öğretmenlerin lehine olduğu belirlenmiş olup, pandemi öncesi süreçte yapılan Özenoğlu ve arkadaşları (2021)' nın yetişkinler üzerine yapmış olduğu çalışmada medeni durum değişkenine göre evli olan bireylerin lehine istatistiksel olarak anlamlı farklılık görülmüşken, Güngör (2019)'ün bireysel ve grup şeklinde verilen sağl1klı beslenme konusunda eğitimin sonucunda besin tercihi konusunda, medeni durum değişkenine göre farklılık oluşturmadığ1 görülmüştür.

Araştırmada öğretmenlerin branş değişkenine göre sağlıklı beslenmeye karşı tutum düzeyinin pandemi süreci öncesi ve pandemi süreci boyunca alt boyutlar ile değerlendirilmiş olup tüm alt boyutlarda ortalamalarına göre istatistiksel olarak anlamlı farklılık görülmüştür. Pandemi öncesi ölçeğin alt boyutları değerlendirildiğinde, beslenme hakkında bilgi düzeyi beden eğitimi ve spor öğretmenleri ile branş öğretmenleri arasında oluşmuş olup beden eğitimi ve spor öğretmenlerinin lehine olduğu belirlenmiştir, beslenmeye yönelik tutum düzeylerine bakıldığında branş öğretmenlerinin beden eğitimi ve spor öğretmenleri ile anasınıfi öğretmenlerine göre ortalamalarının yüksek olduğu görülmüştür, olumlu beslenme alışkanlık düzeyi beden eğitimi ve spor öğretmenleri ile anasınıfı öğretmenlerinin branş öğretmenlerine göre ortalamalarının yüksek olduğu görülmüştür ve kötü beslenme alışkanlığı anasınıfi öğretmenlerinden beden eğitimi ve spor öğretmenleri, branş öğretmenleri ve sınıf öğretmenlerinin ortalamaları daha yüksek olduğu belirlenmiştir.

Pandemi döneminde, ölçeğin alt boyutları değerlendirildiğinde, beslenme hakkında bilgi düzeyi beden eğitimi ve spor öğretmenleri ile sınıf öğretmenlerinin branş öğretmenlerine göre ortalamalarının yüksek olduğu görülüp, aynı zamanda sınıf öğretmenlerinin anasınıfı öğretmenlerine göre ortalamalarının yüksek olduğu belirlendi, beslenmeye yönelik tutum düzeyi branş öğretmenlerinin beden eğitimi ve spor öğretmenleri ve anasınıfı öğretmenlerine göre ortalamalarının yüksek olduğu, olumlu beslenme alışkanlığ düzeyi beden eğitimi ve spor öğretmenleri, sınıf öğretmenleri ve anasınıfı öğretmenlerinin ortalamaları sınıf öğretmenlerine göre yüksek olduğu, kötü beslenme alışkanlığı düzeyi branş öğretmenlerinin beden eğitimi ve spor öğretmenleri ve anasınıfi öğretmenlerine göre ortalamalarının yüksek olduğu görülmüsşür. Bu bilgi ve tutumların öğretmenler arasındaki farklılıkların, beden eğitimi ve spor öğretmenlerinin lisans eğitimi döneminde beslenme dersleri okuduklarından aynı zamanda spor yapmanın her zaman iç güdüsel olarak kendi kendini yeterli beslenme konusunda öz denetim halinde tutmasından kaynaklandığı düşünülünebilir. Sınıf öğretmenleri, öğrencilerinin sadece bir dersine girip çıkan bir öğretmen değil, öğrencilerinin tüm derslerinin yanında sosyal ve sportif bütün etkinlik dersleriyle ilgilenmesinden dolayı sınıf öğretmenliği, anne gibi her durumunda sarmalayan bir meslek olmasından kaynakladığı düşünülünebilir 
Sonuç olarak, kadın öğretmelerin besleme konusunda sorumlu oldukları aileleri olmasından dolayı daha hassas oldukları, bekar öğretmenlerin, beslenme konusunda uçlarda oldukları ya tam dikkatli yada olumsuz beslenme alışkanlığı içerisinde oldukları görülmüştür. öğretmenlerin eğitim verdikleri branş düzeyin incelendiğinde, pandemi öncesi beden eğitimi ve spor öğretmenlerinin yüksek olduğu pandemi sürecinde ise sınıf öğretmenlerinin ortalamalarının yüksek olduğu görülmüş olup, sınıf öğretmenlerinin öğrencileri ve aileleri ile daha iç içe olmalarından dolayı daha fazla etkilendikleri düşünülünebilir.

\section{KAYNAKLAR}

Arı, A. G., \& Kanat, M. H. (2020). Covid-19 (Koronavirüs) üzerine öğretmen adaylarının görüşleri. Yüzüncü Yıl Üniversitesi Sosyal Bilimler Enstitüsü Dergisi, (Salgın Hastalıklar Özel Saylsı), 459-492.

Cintoni, M., Rinninella, E., Annetta, M. G., \& Mele, M. C. (2020). Nutritional Management in hospital setting during SARS-CoV-2 Pandemic: A Real-Life Experience. European Journal of Clinical Nutrition, 74(5), 846-847.

Çakın, M., \& Akyavuz, E. K. (2020). Covid-19 Süreci ve eğitime yansıması: Öğretmen görüşlerinin incelenmesi. International Journal Of Social Sciences and Education Research, 6(2), 165-186.

Demir, G. T., \& Cicioğlu, H. İ. (2019). Sağlıklı beslenmeye ilişkin tutum ölçeği (SBİTÖ): Geçerlik ve güvenirlik çalışması. Gaziantep Üniversitesi Spor Bilimleri Dergisi, 4(2), 256-274.

Dilber, A., \& Dilber, F. (2020). Koronavirüs (Covıd-19) Salgınının bireylerin beslenme alışkanlıkları üzerindeki etkisi. Journal Of Tourism and Gastronomy Studies, 8(3), 2144-2162.

Dinç, A. (2021). Spor Bilimleri öğrencilerinin sosyal medya bağımlılığı ve sağlıklı beslenme tutumlarının incelenmesi (Iğdır ili örneği). I Ĭdır Üniversitesi Sosyal Bilimler Dergisi, S 25,812-821.

Eren, A. S. (2018). Anketlerin veri girişlerinin kolay bir şekilde yapılmasını sağlayan bilgisayar tabanlı bir yöntemin tanıtımı. Social Mentality and Researcher Thinkers Journal, 4(8), 76-83.

Eskici, G. (2020). Covid-19 pandemisi: Karantina için beslenme önerileri. Anatolian Clinic The Journal Of Medical Sciences, 25, 124-129

Gökay, K. (2020). Spor salonlarına giden bireylerin sağllklı beslenme tutumları ve sosyal görünüş kaygl düzeylerinin belirlenmesi.Yüksek Lisans Tezi, Kars Kafkas Üniversitesi, Sağlık Bilimleri Enstitüsü.

Güngör, E. Ö. (2019). Sağllkl beslenmede bireysel ve grup eğitiminin bireylerin beslenme alışkanlıklarl ve besin seçimi üzerine etkisi. Doktora Tezi, Başkent Üniversitesi, Sağlık Bilimleri Enstitüsü, Ankara.

Hislop, T. G., Bajdik, C. D., Balneaves, L. G., Holmes, A., Chan, S., Wu, E., ... \& Butler, A. L. (2006). Physical and emotional health effects and social consequences after participation in a low-fat, high-carbohydrate dietary trial for more than 5 years. J Clin Oncol, 24(15), 2311-2317.

Muscogiuri, G., Barrea, L., Savastano, S., \& Colao, A. (2020). Nutritional recommendations for covid-19 quarantine. European Journal of Clinical Nutrition, 74(6), 850-851.

Naja, F., \& Hamadeh, R. (2020). Nutrition amid the covid-19 pandemic: A multi-level framework for action. European Journal of Clinical Nutrition, 74(8), 1117-1121.

Özenoğlu, A., Beyza, G., Karadeniz, B., Fatma, K., Bilgin, V., Bembeyaz, Z., \& Saha, B. S. (2021). Yetişkinlerde beslenme okuryazarlığın sağlıklı beslenmeye ilişkin tutumlar ve beden kütle indeksi ile ilişkisi. Life Sciences, 16(1), 1-18.

Reissman, D. B., Watson, P. J., Klomp, R. W., Tanielian, T. L., \& Prior, S. D. (2006). Pandemic influenza preparedness: Adaptive responses to an evolving challenge. Journal of Homeland Security and Emergency Management, 3(2), Article 13

Til, U. (2020). Yeni koronavirüs hastalı̆̆ı hakkında bilinmesi gerekenler. Ayrıntı Dergisi, 8(85).

Tokgöz, P., Ertem, M., Çelik, F., Gökçe, Ş., Saka, G., \& Hatunoğlu, R. (1995). Üniversite öğrencilerinin beslenme alışkanlıklarının saptanmasına ilişkin bir araştırma. Beslenme ve Diyet Dergisi, 24(2), 229-238.

Vançelik, S., Önal, S. G., Güraksın, A., \& Beyhun, E. (2007). Üniversite Öğrencilerinin beslenme bilgi ve alışkanlıkları ile ilişkili faktörler. TSK Кoruyиси Hekimlik Bülteni, 6(4), 242-248. 